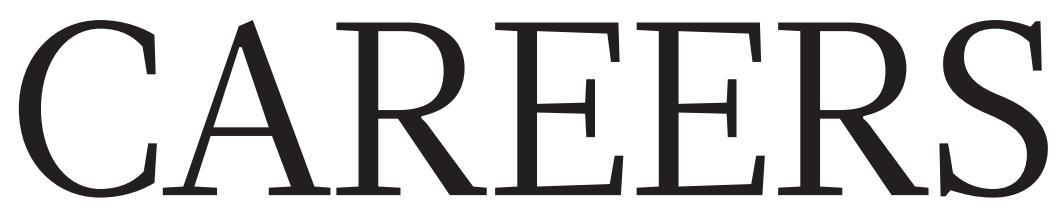

MENTORING Put together an agenda for meetings with your supervisor $\mathbf{p . 2 7 7}$

SHARE Tell us your career story at naturecareerseditor@nature.com ff Follow us at facebook.com/naturejobs Follow us on twitter.com/naturejobs

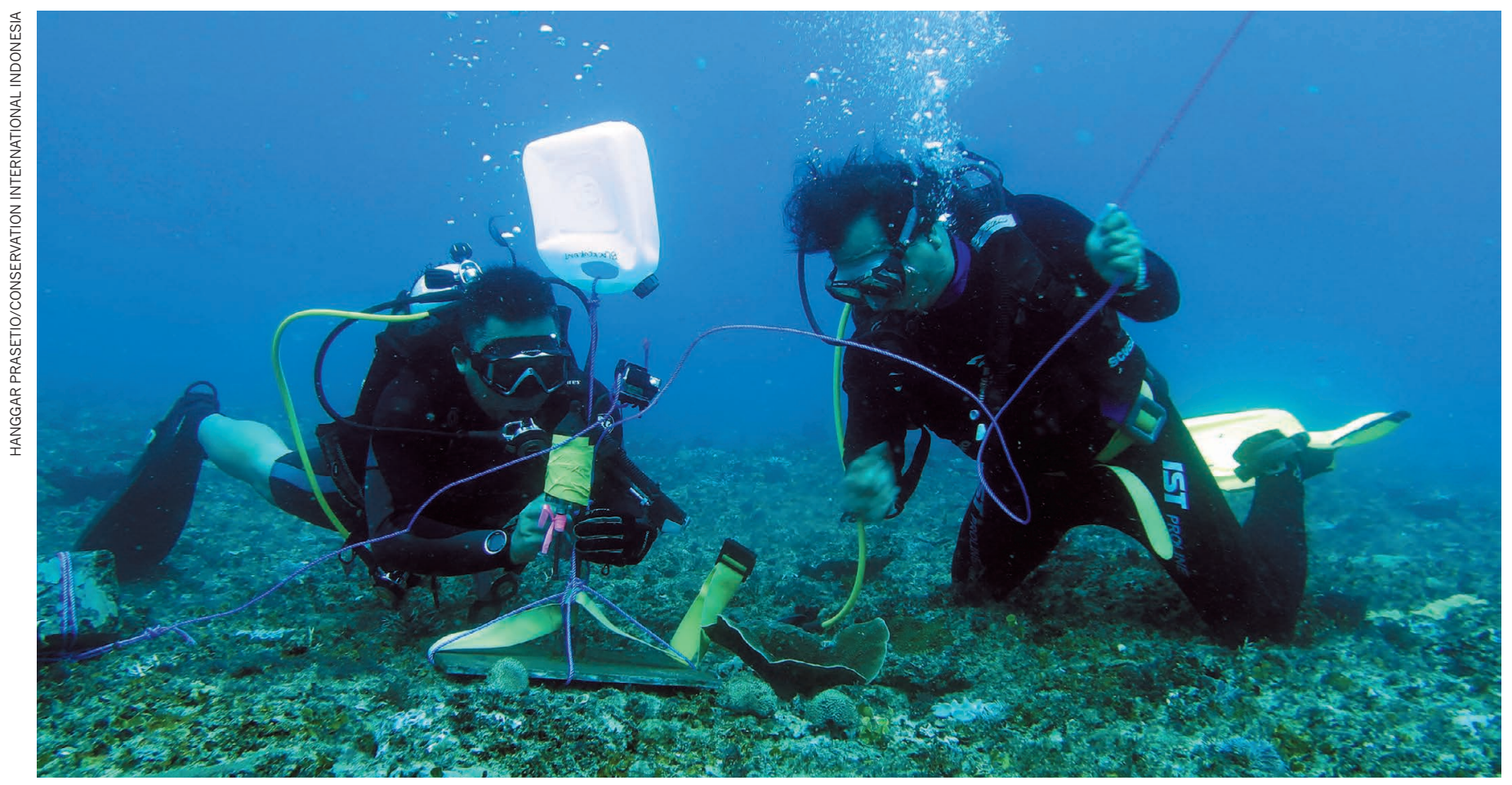

Colleagues of marine biologist Rob Williams install ill-fated hydrophones off the coast of Uluwatu, on the Indonesian island of Bali.

\title{
SETBACKS
}

\section{That sinking feeling}

\section{Plenty can go wrong in field research but there are ways to rescue the work.}

\section{BY EMILY SOHN}

$\mathrm{I}$ 2011, marine-mammal biologist Lucy Keith-Diagne applied for a permit from the Republic of Mali to export manatee tissue and bone samples to the United States for genetic analysis. She had to wait 13 months for the permit to come through - and when nine samples of West African manatees (Trichechus senegalensis) were eventually shipped out, six of them were lost during US Customs and Immigration inspection. The mishap was just one of many fieldwork roadblocks that Keith-Diagne, at the African Aquatic Conservation Fund in Senegal, has faced in her career. Political unrest in Mali has since prevented her team from acquiring further samples of the marine mammals.

It is impossible to predict what might happen during data collection - storms, vandalism, cultural clashes, to name a few of the threats that can pop up. Maintaining a sense of humour is key, say experienced field scientists. They also recommend communicating with local residents and property owners whose permissions might be necessary, conducting multiple projects simultaneously, and viewing each fieldwork flop as an opportunity to be better prepared next time. It also helps to be frank with funders about the need for a project's budget to accommodate the likelihood of lost data or other disasters.

"You learn important things from all your mistakes," says Christer Nilsson, an emeritus landscape ecologist at Umeå University in Sweden. "You have to see the opportunities that might appear if things happen - and be ready to turn your study into something else."

Fieldwork disruption can be particularly tough in early-career stages, when stakes are high. As a first-year PhD student in ecology and evolution at Rutgers University in New
Jersey, Orin Robinson wanted to identify why foxes on a nearby barrier island were overbreeding and eating shorebirds. He spent the spring and summer of 2010 walking a 5.6-kilometre path twice a week to set traps and survey breeding birds.

By the end of the summer, he had collected nine foxes and several other creatures, which were euthanized by a local US Department of Agriculture office. After storing the carcasses in his lab's freezer for later analysis, Robinson expected to make further discoveries and develop follow-up projects on nearby islands - work that would form the bulk of his dissertation. Then he learnt that the lab freezer had been unplugged for days. All his samples were ruined. Starting again would have put him a year behind on his graduate degree.

Robinson decided to use data that had been previously collected by others to conduct a theoretical study that didn't require new 
- field collections. Eight years later, he uses field data for his research, but he doesn't collect it himself and most of his work remains theoretical. He recommends that colleagues who rely on fieldwork for data collection should plan for when things go wrong. "I hate to say, 'Expect the unexpected,' because that is supercliché and doesn't help," says Robinson, who is now a quantitative ecologist at the Cornell Lab of Ornithology in Ithaca, New York. "But be prepared, and don't put all your eggs in that fieldwork basket. Have a Plan B."

\section{SAFETY NET}

Back-up plans remain essential even decades into a career, and they can be as simple as expanding the scope of a study or running multiple projects at once, while the opportunity is there, Nilsson says. He has lost data to floods, and from the behaviour of teenagers and property owners - incidents that have led him to set up extra experimental plots of land and to put out extra equipment in case some gets lost or destroyed. "You have to be overambitious and plan for a higher number of experiments in case you lose data," Nilsson says.

Making extra copies of files and backing up data are also important, says Keith-Diagne. She advises thinking about how to redo a project or recoup lost data before fieldwork begins. In addition, preventing disaster might require taking extra care with the equipment that matters most, and building maintenance expenses into budgets. It is often helpful, she adds, to seek a funding margin to accommodate potential losses and unexpected incidents. As soon as something does go wrong, she recommends telling funders straight away, and proposing ideas for what to do next.

It can help as well to look for funders who are willing to be flexible, says Kate Jones, a conservation biologist at University College London. Her research on bats takes her around the world, and her budgets often include the cost of rangers for protection. During an eight-day scouting trip in Mongolia in 2008, she and her colleagues were stranded in a truck in a flooded river. Miraculously, someone spotted the vehicle and helped tow it to safety. Jones had rescued her equipment and knew that the project's funder was willing to allow for disaster. "You try to budget for more than you need," Jones says.

Researchers need to be willing to put aside emotions and even start afresh, says Deborah Roach, an evolutionary ecologist at the University of Virginia in Charlottesville. In 1986, as a researcher at Duke University in Durham, North Carolina, Roach set up what was meant to be a long-term study of plant ageing in a field on campus that had been used for research for the previous 30 years. She and her colleagues planted 27,000 seedlings over four years and planned to follow them for the next decade. Four years into the project, the university decided to build an art museum on the site. Roach tried in vain to stop the plan, and construction ended the study, which would have been the first of its kind. "It was crushing," Roach says.

Researchers should think about how to publish results and put ideas to fresh use, even when projects are destroyed, experts say. And second chances can offer opportunities to learn from mishaps. Roach started the experiment again, after moving to Virginia. This time, she spent a lot of time searching for the ideal spot and picked one on private land that was guaranteed to be free of interruption in the long term. In the meantime, she managed to salvage data from the work at Duke to publish two papers that analysed the effects of an El Niño event on the plants during the 4.5 years that the original study had lasted ${ }^{1,2}$. It was not the original intent of the study. "I had to take a fresh look at what we did have and say, 'Given this is it, what can we do?"' Roach says.

Publications and funding applications tend to gloss over the data that researchers didn't get, but some find it valuable to disclose obstacles faced. In 2017, Rob Williams, a marine biologist at Oceans Initiative, a non-profit organization in Seattle, Washington, embarked on a study of ocean noise. He and colleagues placed six hydrophones (microphones that detect underwater sound) into the ocean for a week. But they were able to retrieve only three. One of those was broken, and one had been in water too shallow for it to be useful, leaving them with data from just one of the six. They submitted a paper that included an explanation for the loss of five of the six hydrophones ${ }^{3}$. "The reviewer actually commented to say that was the first time they had ever seen someone be honest," Williams says. "Most people would've said, 'We put out one hydrophone, and this is what we heard."

He adds: "Sharing honestly what people have actually dealt with will help to create a culture where people don't feel so alone or so singly responsible. If you're honest that animals are unpredictable and equipment can fail, it will take a lot of pressure off. Unexpected events are the rule and not the exception."

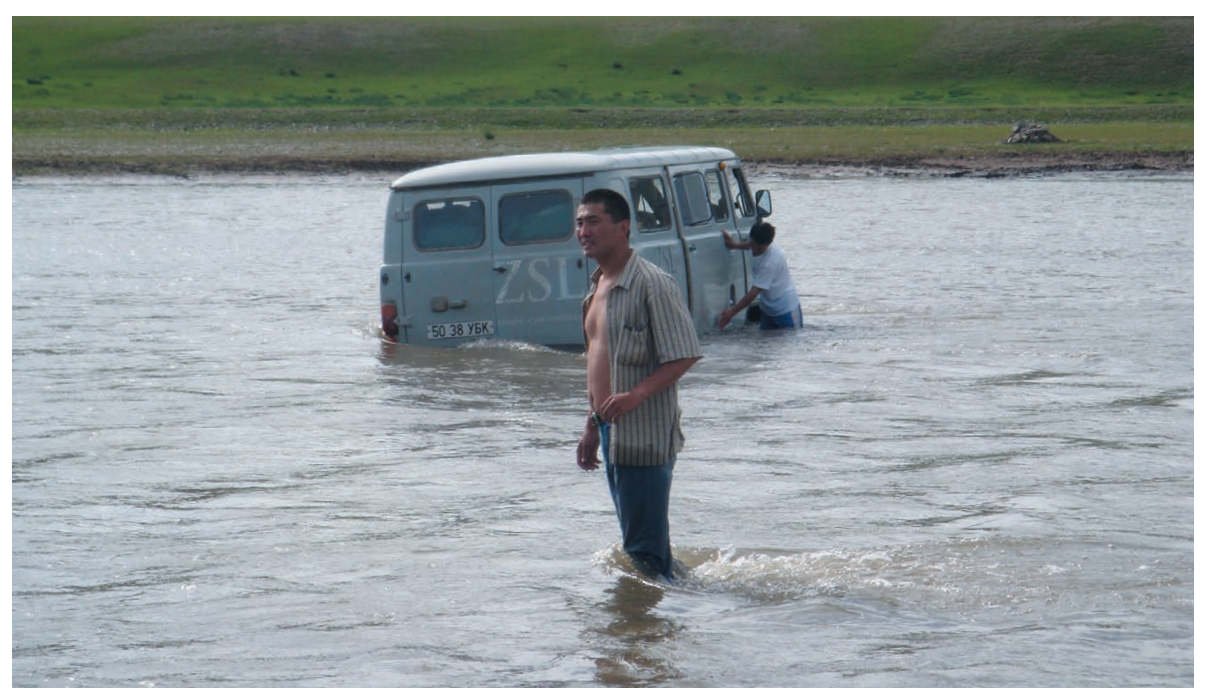

A truck used by conservation biologist Kate Jones lies stuck in a river during a research trip in Mongolia.
Some of the most frustrating cases of fieldwork interference happen because of human behaviour - sometimes intentional. In the mid-1980s, Nilsson set up 25 experimental strips of ground, to study seed dispersal on a shoreline of the Storvindeln lake, in Sweden's Vindel River, over a five-year period. Each strip contained five plots, which he and colleagues marked carefully with plastic stakes. In the second year, when Nilsson checked the plots, he found all but two sets of the stakes piled up in a nearby forest. There was no way to work out where the sticks had been in the sandy ground. Vandalism had ended the experiment, leaving the team to publish a study using only the first year of data ${ }^{4}$.

Some 15 years later, Nilsson and a colleague marked plots for a different study, with stakes that they pushed farther into the ground to make them less visible. But they had not sought permissions from a farmer who owned some of the land, and who put his cows on one of the plots, ruining that plot. At least this time, they had enough other plots to publish a paper. "I learned that it could be a good idea to talk with landowners," Nilsson says now.

\section{BEACH CULTURE}

Rochelle Constantine, a marine biologist at the University of Auckland in New Zealand, surveys species of stranded whales and dolphins that wash up on New Zealand's beaches. The project, which depends on collecting tissue samples for DNA analyses, started in the early 1990s. To collect tissue, the group must get permission from the indigenous Maori population, who have legal rights to the country's whales. At first, the Maori, who have strong cultural affinities to the animals, didn't like the idea of scientists cutting into them. But by listening to, respecting and talking with members of the community, Constantine says, the scientists eventually earned their trust and can now access samples from most stranded animals. The typical procedure is to take tissue samples after the Maori bless and name stranded whales. 
But even good communication can't prevent all mishaps. In December 2010, Constantine's team learnt that two Hector's beaked whales (Mesoplodon hectori) had washed ashore in northern New Zealand. After her team took samples, rangers buried them. Several months later, genetic analysis revealed that the animals were actually spade-toothed whales (Mesoplodon traversii). It was the first time scientists had seen entire specimens of the rare creatures, rather than isolated bones and teeth. Realizing that the discovery was a big deal, the researchers returned to the site to retrieve the skeletons. When they got there, the elder whale's skull was missing. Constantine suspects that the skull had either been washed away or perhaps removed.

When another skull had gone missing in the 1990s, her colleagues had spotted it in a remote community, on a doorstep. Asked about the skull, the homeowner was happy to leave it where it was. It was a frustrating situation, but Constantine says now that maintaining relationships is more important than any single specimen.

Having an open mind about fieldwork failures can, in some cases, lead to new insights and ideas, adds Erin Ashe, a marine biologist with Oceans Initiative (who is married to Rob Williams). As a graduate student, Ashe planned to study Pacific white-sided dolphins in British Columbia, Canada. On her first day of fieldwork for her PhD in 2009, she found hundreds of dolphins and began taking pictures for photo identification. Soon, the dolphins started acting strangely as they raced for the shore. Ashe worried that she had disturbed the animals and that, if they were so easy to startle, it might be impossible to complete her study. Then a killer whale attacked and killed one of the dolphins in front of her.

The unexpected interference - by an animal, in this case - led her to shift her research and study predation instead. That work formed the basis of two of her thesis chapters, and paved the way for a major grant from the US Navy and subsequent studies that turned out to be more interesting than her original plan. "Fieldwork is all about flexibility," Ashe says, adding that the uncertainty and challenge is part of what attracted her to fieldwork. "It makes things interesting - the fact that I can go out there and discover new things or see things that have never been seen before." -

Emily Sohn is a freelance journalist in Minneapolis, Minnesota.

1. Roach, D. A. Ecology 84, 749-756 (2003)

2. Roach, D. A. \& Gampe, J. Am. Nat. 164, 60-69 (2004).

3. Williams, R. et al. Oceanography http://doi.org/ ctkw (2018).

4. Grelsson, G. \& Nilsson, C. Freshw. Biol. 26, 199-207 (1991)

5. Merritt, D. M., Nilsson, C. \& Jansson, R. Ecol. Monogr. 80, 609-626 (2019).

COLUMN

\section{The importance of agendas}

\section{Have talking points ready for meetings with your supervisor, say Tess L. Veuthey and Samuel Thompson.}

A s PhD students, we often find ourselves discussing our interactions with our principal investigators (PIs) and swapping advice for improving our mentoring meetings. We have found three practices to be consistently helpful: asking our PIs about all aspects of their job; preparing an agenda for each meeting; and negotiating new experiments without explicitly saying 'no'.

We both see our $\mathrm{PhD}$ programmes as academic apprenticeships. One crucial goal is to flesh out our understanding of life as a PI. By collaborating with our PIs and observing how they work, we learn how to plan experiments and how to write papers. But we don't get to practise other skills, such as interacting with journal editors and recruiting lab members. To learn these, we ask our PIs about how they plan when running the lab. For example, when people leave Samuel's lab, he asks his PI about her plans for reallocating shared lab responsibilities.

Face-to-face time with our PIs must be focused, so we use agendas to organize the conversation. We habitually start with, "I made a list of topics I wanted to talk to you about." Tess often starts her agendas with an update on her efforts to develop new research equipment so that her PI can evaluate their importance to her project. When Tess was designing new probes for electrophysiological recordings, her PI helped her to balance testing new research hardware against continuing data collection with older technology. Preparing an agenda also helps us to learn our PIs' priorities. Before Samuel discusses new data or his progress on experiments, he always asks his PI, "Is there anything else you wanted to talk about?"

Setting an agenda helps us to introduce uncomfortable topics. For example, including 'summer course funding' in her agenda helped Tess to request funding for a course on computational neuroscience - something she had been avoiding doing for weeks. It turned out that Tess's PI was happy to provide support.

We and our PIs see our projects from different perspectives. Whereas they focus on the big picture, we wrestle with implementation. Because of this disconnect, we can discount their advice as being out of touch. Conversely, if we shoot down all their suggestions for ambitious

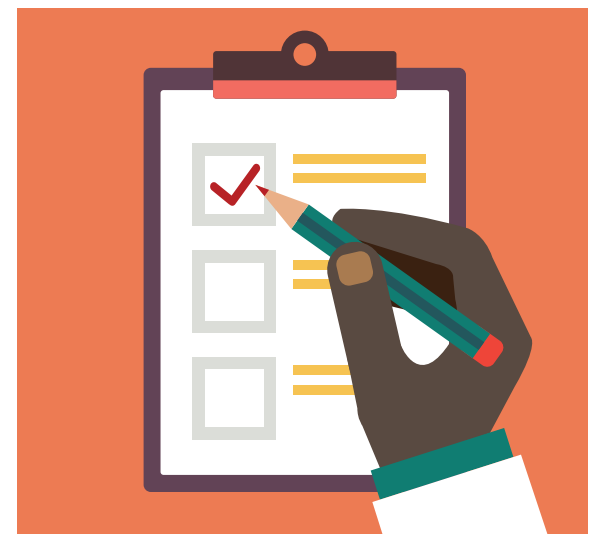

experiments, our PIs grow frustrated.

When we realize we're saying 'no', we try to engage with our PI's idea by asking specific questions. These moments of potential conflict can turn into opportunities to hash out experimental strategies. We might say, "I think that would be an exciting direction, and it would be helpful for me if we could discuss specific metrics for measuring that result." Instead of searching for flaws, we try to discuss a realistic road map for an optimistic outcome.

We are never going to be perfect mentees. We remind each other to take an active role in our mentoring relationships and to seek mentorship from multiple sources. Tess has great conversations with her physician-scientist PI about her clinical interests as an MD-PhD student. But she also has female mentors for advice about working within a male-dominated field. Samuel routinely discusses personal career goals with his PI, but relies on collaborators for advice on experimental techniques outside his PI's expertise.

Discussions on mentorship often place the onus solely on the mentor. But, as mentees, we also need to ask ourselves, "What's working and not working in this interaction? Where can I try something new? What would be ideal?" No template can solve all PI-student concerns. But simple steps can go a long way in helping these relationships to thrive.

Tess Veuthey is an MD-PhD student in neuroscience and Samuel Thompson is a PhD student in biophysics at the University of California, San Francisco. 